\title{
Desempenho de cultivares e híbridos de milheto em solo submetido a compactação ${ }^{1}$
}

\author{
Christianne V. Guimarães ${ }^{2}$, Renato L. de Assis ${ }^{3}$, Gustavo A. Simon ${ }^{4}$, \\ Fábio R. Pires ${ }^{5}$, Rodrigo L. Ferreira ${ }^{6}$ \& Danilo C. dos Santos ${ }^{7}$
}

\begin{abstract}
RESUMO
Objetivou-se, neste trabalho, avaliar o crescimento aéreo e radicular de cultivares e híbridos de milheto em solo submetido a quatro níveis de compactação do solo. Foram utilizados sete híbridos de milheto Pennisetum glaucum L. (40425, 40853, 41312, 51499, 60018, 60019 e ADR7010) e as variedades ADR300 e ADR500; aos 30 dias após o plantio determinaram-se as massas da matéria seca da parte aérea e das raízes, a densidade do comprimento radicular e o diâmetro médio radicular. Na densidade de 1,74 $\mathrm{Mg} \mathrm{m}^{-3}$ as cultivares e híbridos de milheto apresentaram uma redução elevada da massa verde da parte aérea, massa seca da parte aérea, altura de plantas e área foliar. Os híbridos 40853 e 60019 apresentaram comportamento inferior aos demais híbridos e cultivares na produção de matéria verde e seca da parte aérea e altura de plantas na densidade de 1,65 Mg m³. As cultivares ADR500 e ADR300 e os híbridos 40425 e 51499 se destacaram na produção de massa verde e seca e altura de plantas na densidade de $1,65 \mathrm{~kg} \mathrm{~m}^{-3}$. A maior densidade de comprimento radicular média entre as cultivares de milheto foi verificada na densidade do solo de 1,46 $\mathrm{Mg} \mathrm{m}^{-3}$. A cultura do milheto demonstrou potencial como planta descompactadora do solo.
\end{abstract}

Palavras-chave: densidade do solo, sistema radicular, plantas de cobertura

\section{Performance of cultivars and hybrids of millet in a soil submitted to compaction}

\begin{abstract}
The objective of this study was to evaluate the root and aerial growth of cultivars and hybrids of pearl millet in soil under four levels of soil compaction. Seven hybrids of pearl millet - Pennisetum glaucum L. (40425, 40853, 41312, 51499, 60018, 60019 and ADR7010) and ADR300 and ADR500 varieties were used. At 30 days after planting, the dry mass of shoots and roots, root length density and root mean diameter was determined. In the density of $1.74 \mathrm{Mg} \mathrm{m}^{-3}$ varieties and hybrids of pearl millet showed a high reduction of green matter, dry mass of shoots, plant height and leaf area. Hybrids 40853 and 60019 produced less than other hybrids and cultivars in the production of green and dry matter of shoots and plant height in the density of $1.65 \mathrm{Mg} \mathrm{m}^{-3}$. The ADR500 and ADR300 varieties and hybrids 40425 and 51499 excelled in the production of green and dry mass and plant height in the density of $1.65 \mathrm{~kg} \mathrm{~m}^{-3}$. The highest mean root length density among the cultivars of millet was found at a density of $1.46 \mathrm{Mg} \mathrm{m}^{-3}$. The millet crop showed potential for descompaction of soil.
\end{abstract}

Key words: soil density, root system, cover plants

\footnotetext{
1 Parte da Dissertação de Mestrado do primeiro autor apresentada ao Programa de Pós-Graduação em Produção Vegetal da UniRV

2 Bióloga, Colégio Estadual Olynto Pereira de Castro. Rua Juca Baylão, Qd. 36 Lt. 20, 56, Setor Morada do Sol, CEP 75909-050, Rio Verde, GO Fone: (64) 3622-0015. E-mail:chrisbiologia@yahoo.com.br

${ }^{3}$ Instituto Federal Goiano, Câmpus Iporá, Rodovia GO 060, Km 01, Zona Rural, CEP 76200-000, Iporá, GO. Fone/Fax: (64) 3674-0400. E-mail: relassis@bol.com.br. Bolsista de Produtividade em Pesquisa do CNPq

${ }^{4}$ UniRV, Fazenda Fontes do Saber, CP 104, CEP 75901-970, Rio Verde, GO. Fone: (64) 3611-2262. E-mail: simon@unirv.edu.br

${ }^{5}$ UFES, Rodovia BR 101 Norte, Km 60, Bairro Litorâneo, CEP 29932-540, São Mateus, ES. E-mail: fabiopires@ceunes.ufes.br. Bolsista de Produtividade em Pesquisa do CNPq

${ }^{6}$ Engenheiro Agrônomo. UniRV - Universidade de Rio Verde

${ }^{7}$ Engenheiro Agrônomo. Indústria e Comércio de Fertilizantes Rifertil Ltda., Rua dos trabalhadores, Setor industrial s/n, CEP 75900-000, Rio Verde, GO. E-mail: cabralagrorv@hotmail.com
} 


\section{INTRODUÇÃO}

A compactação do solo é resultado da ação de forças externas e internas que atuam no solo; as forças externas resultam do tráfego de máquinas e equipamentos agrícolas e as internas são devidas aos ciclos de umedecimento e secagem, expansão e contração da massa do solo. Para o rompimento da camada compactada os métodos mais utilizados são a utilização de subsoladores e escarificadores, penetrando na camada compactada e amenizando o efeito do impedimento mecânico ao desenvolvimento das raízes; outra alternativa visando reduzir e amenizar os efeitos da compactação do solo se refere ao uso de espécies que tenham sistema radicular vigoroso com capacidade de crescimento em solos com altas resistências à penetração.

As plantas de cobertura utilizadas como descompactadoras de solo, proporcionam um rompimento mais uniforme da camada compactada em razão da uniformidade da distribuição de raízes ao longo do perfil.

A cultura do milheto (Pennisetum glaucum (L.) R. Br.) tem-se expandido de forma acelerada no Cerrado Brasileiro em razão da sua versatilidade de usos, rusticidade, crescimento rápido e capacidade de romper camadas compactadas. A cultura apresenta resistência à seca, adaptação a solos de baixa fertilidade e excelente capacidade de produção de massa seca; atualmente, o uso do milheto na agricultura brasileira vem aumentando de forma rápida para a produção de palhada no sistema de plantio direto, cada vez mais empregado no Cerrado; além disto, possui um sistema radicular profundo que descompacta e estrutura o solo e também recicla nutrientes (Boer et al., 2007).

A utilização de milhetos híbridos tornou-se oportuna com a necessidade de materiais mais produtivos, tanto para a produção de grãos quanto para a produção de forragem. Através do melhoramento genético se desenvolveram materiais com potenciais variados atendendo à carência de plantas mais produtivas na produção de grãos e plantas com maior produção de biomassa; entretanto, estudos com milhetos híbridos ainda são incipientes.

Estudos têm demonstrado que a compactação do solo reduz o volume de macroporos, enquanto os microporos quase não sofrem alterações. Assim, o desenvolvimento das raízes é afetado negativamente pela redução dos macroporos, pelo aumento da resistência à penetração das raízes (Stone et al., 2002) pela diminuição da concentração de oxigênio, pela redução da mineralização da matéria orgânica no solo e com a menor difusão de nutrientes e de oxigênio para as raízes diminuindo, assim, a disponibilidade e a absorção de água e de nutrientes (Ribeiro, 1999). Existe uma estreita relação entre porosidade do solo e crescimento radicular, com crescimento de raízes maior onde há maior número e continuidade de macroporos (Stone et al., 2002).
Nas modificações morfológicas nas raízes ocasionadas pelas restrições ao crescimento, estão o aumento do diâmetro radicular e a diminuição do comprimento, tornando-as tortuosas. O crescimento ocorre em pontos de menor resistência oferecidos pelo solo através de poros biológicos deixados por raízes decompostas e fendas naturalmente encontradas no solo. Desta forma, a cultura do milheto tem-se mostrado eficiente para amenizar os efeitos da compactação deixando canais que propiciem condições ao desenvolvimento de raízes da cultura subsequente (Jimenez et al., 2008).

Em seus estudos, Gonçalves et al. (2006) e Jimenez et al. (2008) constataram, utilizando, respectivamente, os milhetos ADR500 e ADR300, que essas cultivares se destacaram quanto ao crescimento em camadas compactadas e abaixo delas, emitindo uma grande quantidade de raízes, mesmo no maior nível de compactação do solo na densidade de $1,60 \mathrm{Mg} \mathrm{m}^{-3}$ proporcionando, assim, diminuição do efeito da compactação do solo. O milheto apresentou-se como a espécie mais indicada para cobertura, por suas características de produção de massa seca e crescimento radicular; entretanto, são poucos os estudos com milhetos híbridos na presença de camada compactada.

Visou-se, no presente estudo, avaliar o crescimento aéreo, crescimento radicular de cultivares e híbridos de milheto em função da compactação em subsuperfície em um Latossolo Vermelho distroférrico.

\section{Material e Métodos}

O experimento foi realizado no período de fevereiro a abril de 2007 em casa de vegetação da Faculdade de Agronomia da FESURV - Universidade de Rio Verde. Foram utilizadas amostras deformadas de solo proveniente do horizonte A de um Latossolo Vermelho distroférrico, coletados na camada de 0-20 cm de um solo de textura argilosa. Após secagem ao ar o solo foi passado em peneira com malha de $2 \mathrm{~mm}$ e submetido à caracterização química e textural (Tabela 1) conforme metodologia proposta pela EMBRAPA (1997).

A saturação de bases do solo foi elevada para $50 \%$ por meio da adição de calcário e o solo umedecido a $80 \%$ da capacidade de campo e armazenado em sacos plásticos para incubação úmida, por 15 dias. O delineamento utilizado foi em blocos ao acaso em esquema fatorial $9 \times 4$ (sete cultivares de híbridos de milheto e duas variedades e quatro níveis de densidades do solo) com quatro repetições.

Foram utilizados sete cultivares de milheto híbrido Pennisetum glaucum L. (40425, 40853, 41312, 51499, 60018, 60019 e ADR7010) e as variedades de milheto ADR300 e ADR500. Os milhetos híbridos são produtos de melhoramento genético desenvolvido pela Bonamigo Melhoramentos. A variedade ADR300 é recomendada para produção da palhada no sistema plantio direto, enquanto a variedade ADR500 é

Tabela 1. Caracterização química, análise textural e teor de água na capacidade de campo do horizonte $\mathrm{A}$ de um Latossolo Vermelho distroférrico

\begin{tabular}{|c|c|c|c|c|c|c|c|c|c|c|c|c|}
\hline \multirow{2}{*}{$\mathrm{pH}\left(\mathrm{CaCl}_{2}\right)$} & $\mathbf{P}$ & $\mathrm{H}+\mathrm{Al}$ & $K$ & $\mathrm{Ca}$ & $\mathrm{Mg}$ & CTC & \multirow{2}{*}{$\begin{array}{l}\mathbf{V} \\
\%\end{array}$} & M.0.* & C.C. ${ }^{*}$ & Areia & Silte & Argila \\
\hline & $\mathrm{mg} \mathrm{dm}^{-3}$ & \multicolumn{5}{|c|}{$\mathrm{cmol}_{\mathrm{c}} \mathrm{dm}^{-3}$} & & & & $\mathrm{~g} \mathrm{~kg}^{-1}$ & & \\
\hline 4,0 & 0,30 & 4,1 & 0,08 & 0,22 & 0,17 & 4,59 & 10,2 & 29,4 & 221 & 350 & 90 & 560 \\
\hline
\end{tabular}

* M.0. - Matéria orgânica; C.C. - Teor de água na capacidade de campo a -0,006 MPa 
recomendada para pastejo e capineira. Os híbridos ADR7010, 40425, 40853, 41312 e 51499 apresentam duplo propósito (produção de massa e grãos) e silageiro, enquanto os híbridos 60018 e 60019 são específicos para produção de massa e grãos.

A unidade experimental constou da sobreposição de três aneis de PVC de $100 \mathrm{~mm}$ de diâmetro interno. A altura dos aneis (superior e inferior) foi de $150 \mathrm{~mm}$ de altura cada um, os quais receberam solo com densidade em torno de 1,10 $\mathrm{Mg} \mathrm{m}^{-3}$, e a altura do anel intermediário com os diferentes níveis de densidade do solo foi de $35 \mathrm{~mm}$. As densidades do solo foram: 1,$28 ; 1,46 ; 1,65$ e $1,74 \mathrm{Mg} \mathrm{m}^{-3}$, representando o grau de compactação de 70, 80, 90 e 95\%, respectivamente. O grau de compactação do solo consiste numa relação entre a densidade do solo atual e a densidade do solo máxima extraída da curva de compactação (Vargas, 1977).

Foram adicionadas quantidades calculadas de solo ao anel central para obtenção dos níveis de compactação do solo desejados; para isto, determinou-se a curva de compactação do solo pelo método de Proctor normal (Nogueira, 1995). De posse dos valores da $\mathrm{Ds}_{\text {máx }}$ determinada em laboratório, que foi de 1,83 $\mathrm{Mg} \mathrm{m}^{-3}$, procedeu-se à compactação do anel intermediário com golpes sucessivos de uma massa de ferro até atingir a espessura de $3,5 \mathrm{~cm}$ com a quantidade de solo para atingir as densidades finais desejadas, estando o solo com a umidade de $75 \%$ da capacidade de campo.

Para evitar o crescimento radicular na interface solo-PVC do anel compactado, foi utilizado o caulim em torno de $1 \mathrm{~cm}$ de espessura que, umedecido, formou uma pasta plástica aderida à parede interna do tubo de PVC; a montagem das colunas se deu com o auxílio de fita adesiva, utilizada para unir os aneis.

O plantio foi realizado na $2^{\mathrm{a}}$ quinzena de fevereiro sendo que foram conduzidas duas plantas por coluna de solo. Realizou-se adubação com $\mathrm{N}$ (ureia), P (superfosfato simples) e K (cloreto de potássio) com aplicação de $150 \mathrm{mg} \mathrm{dm}^{-3}$.

Aos 30 dias após o plantio realizou-se a coleta da parte aérea das plantas seccionando-as rente ao solo; após o corte o material foi pesado para determinação da massa verde e posteriormente colocado em estufa a $65^{\circ} \mathrm{C}$, durante $72 \mathrm{~h}$ e determinada a massa seca da parte aérea. A área foliar foi determinada logo após o corte da parte aérea das plantas sendo obtida indiretamente através do produto das medidas de seu comprimento e largura (medidas com trena) multiplicadas pelo coeficiente de 0,56 (Pires et al., 2007); enfim, a altura de planta foi medida com régua da base até o ápice.

Os vasos foram desmontados e as raízes coletadas por camada (superior, compactada e inferior) e separadas do solo por lavagem em água corrente; em seguida, as raízes foram acondicionadas em sacos-plástico, submersas em solução aquosa com 30\% de álcool etílico; após secagem em papel toalha as raízes foram escaneadas em um scanner de leitura ótica; posteriormente, as amostras foram secadas em estufa a 65 ${ }^{\circ} \mathrm{C}$ por $72 \mathrm{~h}$ e determinada a produção de massa seca das raízes (MSR). O comprimento radicular e o diâmetro médio radicular foram determinados com a utilização do programa Quant Root v. 1.0 adaptado por Amaral (2002); prosseguindo, calculou-se a

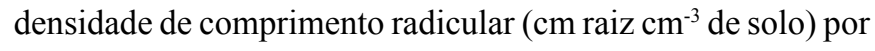
meio da divisão do comprimento de raízes encontrado em cada camada pelo volume do respectivo anel de PVC, ou seja, 1060 $\mathrm{cm}^{3}$ para a camada superior, $1178 \mathrm{~cm}^{3}$ para a camada inferior e $275 \mathrm{~cm}^{3}$ para a camada compactada.

Os resultados foram submetidos à análise de variância e as médias dos parâmetros avaliados pelo teste Tukey a 0,05 de probabilidade e para os níveis de compactação submetidos à análise de regressão.

\section{Resultados e Discussão}

Observaram-se interações significativas nas variáveis avaliadas (Tabela 2) com exceção da altura de plantas, massa seca de raízes e densidade do comprimento radicular na camada compactada e diâmetro radicular nas camadas superior e inferior.

Tabela 2. Significância da análise de variância de massa verde e seca da parte aérea, altura de plantas, área foliar, massa seca de raízes, densidade do comprimento radicular e diâmetro radicular nas diferentes camadas

\begin{tabular}{|c|c|c|c|c|}
\hline \multirow[b]{2}{*}{ Parâmetro } & \multicolumn{4}{|c|}{ Fonte de variação } \\
\hline & $\begin{array}{l}\text { Tratamentos } \\
\text { (T) }\end{array}$ & $\begin{array}{l}\text { Densidade } \\
\text { (D) }\end{array}$ & TxD & $\begin{array}{l}\text { CV } \\
\text { (\%) }\end{array}$ \\
\hline $\begin{array}{l}\text { Massa verde da } \\
\text { parte aérea (MVPA) }\end{array}$ & ** & $\star \star$ & $\star$ & 22,31 \\
\hline $\begin{array}{l}\text { Massa seca da } \\
\text { parte aérea (MSPA) }\end{array}$ & $\star \star$ & $\star \star$ & $\star \star$ & 16,16 \\
\hline Altura de plantas & ** & ** & ns & 11,78 \\
\hline Área foliar & ns & ** & * & 22,92 \\
\hline Camadas & \multicolumn{4}{|c|}{ Massa seca de raízes (MSR) } \\
\hline Camada superior & $\star \star$ & $\star \star$ & $\star \star$ & 27,41 \\
\hline $\begin{array}{l}\text { Camada } \\
\text { compactada }\end{array}$ & ns & * & ns & 63,59 \\
\hline Camada inferior & $\star \star$ & $\star \star$ & $\star \star$ & 44,71 \\
\hline & \multicolumn{4}{|c|}{ Densidade do comprimento radicular (DCR) } \\
\hline Camada superior & $* *$ & $* *$ & $* *$ & 27,41 \\
\hline $\begin{array}{l}\text { Camada } \\
\text { compactada }\end{array}$ & ns & * & ns & 63,59 \\
\hline Camada inferior & $\star \star$ & $\star \star$ & $\star \star$ & 44,71 \\
\hline & \multicolumn{4}{|c|}{ Diâmetro radicular (DR) } \\
\hline Camada superior & ** & ns & ns & 25,34 \\
\hline $\begin{array}{l}\text { Camada } \\
\text { compactada }\end{array}$ & ns & ns & * & 18,23 \\
\hline Camada inferior & * & ** & ns & 35,89 \\
\hline
\end{tabular}

Os dados da Tabela 3 mostram que na densidade de 1,28 $\mathrm{Mg} \mathrm{m}^{-3}$ não ocorreu diferença entre as cultivares em todos os parâmetros avaliados, comportamento que demonstra que em baixas densidades $\left(1,28 \mathrm{Mg} \mathrm{m}^{-3}\right)$ não ocorrem limitações no crescimento da parte aérea das plantas. Resultados semelhantes foram encontrados por Foloni et al. (2006) ao verificarem que a compactação do solo não afetou significativamente a produção de massa seca da parte aérea das plantas de plantas de cobertura na densidade do solo até $1,56 \mathrm{Mg} \mathrm{m}^{-3}$.

Nas densidades de 1,28, 1,46 e 1,74 $\mathrm{Mg} \mathrm{m}^{-3}$ a MVPA foi semelhante entre as espécies estudadas (Tabela 3). Ocorreu maior redução da MVPA entre as densidades de 1,65 e 1,74 $\mathrm{Mg} \mathrm{m}^{-3}$ de $41 \%$ em média; na densidade de $1,65 \mathrm{Mg} \mathrm{m}^{-3} \mathrm{o}$ híbrido 40853 apresentou comportamento inferior ao das variedades ADR300 e ADR500 o que demonstra a maior adaptação das variedades às condições de compactação do solo em relação ao híbrido na produção de MVPA. No maior nível 
Tabela 3. Massa verde da parte aérea (MVPA), massa seca da parte aérea (MSPA), altura de plantas e área foliar de híbridos e cultivares de milheto considerandose as densidades do solo na camada compactada

\begin{tabular}{|c|c|c|c|c|}
\hline \multirow{2}{*}{ Tratamento } & MVPA & MSPA & \multirow{2}{*}{$\begin{array}{l}\text { Altura de planas } \\
\text { (cm) }\end{array}$} & \multirow{2}{*}{$\begin{array}{l}\text { Área foliar } \\
\text { (cm²) }\end{array}$} \\
\hline & \multicolumn{2}{|c|}{ (g) } & & \\
\hline & \multicolumn{4}{|c|}{ Densidade do solo: $\left(1,28 \mathrm{Mg} \mathrm{m}^{-3}\right)$} \\
\hline ADR 300 & $37,20 \mathrm{a}$ & 8,14 a & $73,7 \mathrm{a}$ & 524,4 a \\
\hline ADR 500 & $33,25 \mathrm{a}$ & $7,05 \mathrm{a}$ & $68,2 \mathrm{a}$ & $482,8 \mathrm{a}$ \\
\hline ADR 7010 & $29,87 \mathrm{a}$ & $7,88 \mathrm{a}$ & $63,2 \mathrm{a}$ & $562,6 \mathrm{a}$ \\
\hline 40425 & $33,25 \mathrm{a}$ & $7,40 \mathrm{a}$ & $66,3 \mathrm{a}$ & $457,3 \mathrm{a}$ \\
\hline 40853 & $35,70 \mathrm{a}$ & $8,49 \mathrm{a}$ & $70,1 \mathrm{a}$ & $514,5 \mathrm{a}$ \\
\hline 41312 & $29,92 \mathrm{a}$ & $6,77 \mathrm{a}$ & $62,0 \mathrm{a}$ & $413,1 \mathrm{a}$ \\
\hline 51499 & $39,62 \mathrm{a}$ & $7,25 \mathrm{a}$ & $62,5 \mathrm{a}$ & $478,7 \mathrm{a}$ \\
\hline 60018 & $31,35 \mathrm{a}$ & $6,79 \mathrm{a}$ & $57,5 \mathrm{a}$ & $477,4 \mathrm{a}$ \\
\hline 60019 & $29,95 \mathrm{a}$ & $6,98 \mathrm{a}$ & $57,5 \mathrm{a}$ & $511,4 \mathrm{a}$ \\
\hline \multirow[t]{2}{*}{ Média } & 33,34 & 7,41 & 64,5 & 491,3 \\
\hline & \multicolumn{4}{|c|}{ Densidade do solo: $\left(1,46 \mathrm{Mg} \mathrm{m}^{-3}\right)$} \\
\hline ADR 300 & $31,02 \mathrm{a}$ & 7,46 abcd & $73,2 \mathrm{a}$ & $465,0 a b$ \\
\hline ADR 500 & $37,72 \mathrm{a}$ & $8,73 a b$ & $62,3 a b$ & $533,0 a b$ \\
\hline ADR 7010 & $32,52 \mathrm{a}$ & 6,82 abcd & $63,3 a b$ & 556,9 a \\
\hline 40425 & $37,47 \mathrm{a}$ & 8,20 abc & $69,7 \mathrm{a}$ & 340,8 b \\
\hline 40853 & $35,82 \mathrm{a}$ & 7,66 abcd & $66,2 \mathrm{ab}$ & $510,7 a b$ \\
\hline 41312 & $24,72 \mathrm{a}$ & $5,84 \mathrm{~cd}$ & $62,0 a b$ & $350,6 a b$ \\
\hline 51499 & $32,35 \mathrm{a}$ & 6,67 bcd & $71,7 \mathrm{a}$ & $459,4 a b$ \\
\hline 60018 & $37,85 \mathrm{a}$ & $9,27 \mathrm{a}$ & $65,8 a b$ & $506,4 a b$ \\
\hline 60019 & $24,05 \mathrm{a}$ & $5,53 d$ & $53,2 \mathrm{~b}$ & $376,1 a b$ \\
\hline \multirow[t]{2}{*}{ Média } & 32,61 & 7,35 & 65,2 & 455,4 \\
\hline & \multicolumn{4}{|c|}{ Densidade do solo: $\left(1,65 \mathrm{Mg} \mathrm{m}^{-3}\right)$} \\
\hline ADR 300 & $37,57 \mathrm{ab}$ & 8,32 ab & $76,1 \mathrm{a}$ & $458,5 a b$ \\
\hline ADR 500 & $42,82 \mathrm{a}$ & 10,54 a & $73,5 a b$ & $509,5 a b$ \\
\hline ADR 7010 & $30,82 a b c$ & $6,74 \mathrm{bc}$ & $68,3 a b$ & $486,2 a b$ \\
\hline 40425 & $42,85 \mathrm{a}$ & $8,99 a b$ & 78,8 a & 586,1 a \\
\hline 40853 & $21,67 \mathrm{c}$ & $5,11 \mathrm{C}$ & $59,6 b$ & $331,9 \mathrm{~b}$ \\
\hline 41312 & $32,30 a b c$ & $7,37 \mathrm{bc}$ & $67,0 a b$ & $490,7 \mathrm{ab}$ \\
\hline 51499 & $37,22 a b$ & $8,80 a b$ & $71,2 \mathrm{ab}$ & $391,6 a b$ \\
\hline 60018 & $32,32 a b c$ & $6,88 b c$ & $70,2 a b$ & $503,6 a b$ \\
\hline 60019 & $23,07 \mathrm{bc}$ & $5,81 \mathrm{c}$ & $57,0 \mathrm{~b}$ & $417,3 \mathrm{ab}$ \\
\hline \multirow[t]{2}{*}{ Média } & 33,40 & 7,61 & 69,1 & 463,9 \\
\hline & \multicolumn{4}{|c|}{ Densidade do solo: $\left(1,74 \mathrm{Mg} \mathrm{m}^{-3}\right)$} \\
\hline ADR 300 & $19,22 \mathrm{a}$ & 5,49 a & $55,7 \mathrm{a}$ & $238,4 \mathrm{a}$ \\
\hline ADR 500 & $17,90 \mathrm{a}$ & $5,05 \mathrm{a}$ & $47,0 \mathrm{a}$ & $193,8 \mathrm{a}$ \\
\hline ADR 7010 & $22,92 \mathrm{a}$ & $5,99 \mathrm{a}$ & $54,2 \mathrm{a}$ & $221,8 \mathrm{a}$ \\
\hline 40425 & $17,15 \mathrm{a}$ & $5,36 \mathrm{a}$ & $45,7 \mathrm{a}$ & $171,4 \mathrm{a}$ \\
\hline 40853 & $19,67 \mathrm{a}$ & $5,67 \mathrm{a}$ & $58,7 \mathrm{a}$ & $229,3 \mathrm{a}$ \\
\hline 41312 & $18,90 \mathrm{a}$ & $5,36 \mathrm{a}$ & $48,5 \mathrm{a}$ & $222,8 \mathrm{a}$ \\
\hline 51499 & $20,87 \mathrm{a}$ & $5,38 \mathrm{a}$ & $58,5 \mathrm{a}$ & $155,2 \mathrm{a}$ \\
\hline 60018 & $21,35 \mathrm{a}$ & $5,38 \mathrm{a}$ & $47,2 \mathrm{a}$ & $271,9 a$ \\
\hline 60019 & $18,55 \mathrm{a}$ & $5,12 \mathrm{a}$ & $43,2 \mathrm{a}$ & $214,7 \mathrm{a}$ \\
\hline Média & 19,61 & 5,42 & 50,9 & 213,2 \\
\hline
\end{tabular}

Médias seguidas da mesma letra na coluna não diferem entre si pelo teste de Tukey, a 0,05 de probabilidade

de compactação ( $\mathrm{Ds}=1,74 \mathrm{Mg} \mathrm{m}^{-3}$ ) não ocorreram diferentes na produção de MVPA e MSPA entre as variedades e híbridos de milheto. Resultado semelhante foi encontrado por Silva \& Rosolem (2001) por se tratar de experimentos de curta duração.

Para a MSPA a redução foi de $27 \%$ em média, entre a menor e a maior densidade do solo para todos os tratamentos. Em dados que assemelham aos encontrados por Piffer et al. (2010) em estudo com milheto BN2, amaranto e capim péde-galinha em camadas de solo compactada, observou-se que as espécies apresentaram redução na produção de massa seca com o aumento da densidade do solo na camada compactada; entretanto, o milheto proporcionou a maior quantidade de massa seca na parte aérea, mesmo na presença de camadas compactadas. Esses resultados confirmam o milheto como planta descompactadora de solo e com alta capacidade de produção de massa seca.

O híbrido 60018 apresentou maior produção de MSPA na densidade de $1,46 \mathrm{Mg} \mathrm{m}^{-3}$, porém não diferiu dos milhetos ADR 300, ADR 500, ADR 7010, 40425 e 40853 observandose que na densidade de $1,65 \mathrm{Mg} \mathrm{m}^{-3}$ as variedades ADR500, ADR300 e os híbridos 40425 e 51499 apresentaram maiores acúmulos de MSPA e altura de plantas (Tabela 3). Tais resultados demonstram a diferença de comportamento dos diferentes materiais na presença de camada compactada, fato este justificado em razão da aptidão de cada material (produção de grãos ou massa) desenvolvendo, desta forma, características específicas através do melhoramento genético, que se manifestam de forma diferenciada face a alguma situação de estresse. Referido comportamento dos híbridos 40425 e 51499 com maiores acúmulos de MSPA, se traduz na grande vantagem de se desenvolveram em condições de elevada densidade sem causar redução na produção de massa e grãos.

$\mathrm{Na}$ altura de plantas houve redução de $21 \%$ em média das cultivares de milheto com o aumento do menor para o maior nível de densidade do solo pelo fato de que em solos compactados as plantas não absorvem adequadamente os nutrientes e água haja vista que prejudicam o desenvolvimento de novas raízes, sendo que nelas ocorre a maior taxa de absorção prejudicando também a altura de plantas. Piffer et al. (2010) constataram, em estudo com o milheto $\mathrm{BN} 2$, redução na altura de plantas com aumento da compactação do solo de $73 \%$ entre as densidades de 1,21 e 1,51 $\mathrm{Mg} \mathrm{m}^{-3}$ resultados que comprovam os obtidos no presente estudo.

Analisando a Tabela 3 observa-se que ocorreu redução de $56 \%$ em média na área foliar das cultivares de milheto entre a menor e a maior densidade do solo em razão da menor absorção de água e redução da aeração em solos compactados. Dados semelhantes aos encontrados por Guimarães et al. (2002) que verificaram que a área foliar do feijão decresceu de 4000 para $2000 \mathrm{~cm}^{2}$, quando a densidade aumentou de 1,0 para $1,6 \mathrm{Mg} \mathrm{m}^{-3} \mathrm{em}$ um Latossolo Vermelho perférrico.

$\mathrm{Na}$ densidade de $1,65 \mathrm{Mg} \mathrm{m}^{-3}$ os híbridos $40853 \mathrm{e}$ 60019 apresentaram comportamento inferior ao dos demais híbridos e cultivares na produção de MVPA, MSPA e altura de plantas. A menor área foliar na densidade de $1,65 \mathrm{Mg} \mathrm{m}^{-3}$ foi verificada no híbrido 40853 diferindo apenas do híbrido 40425. Este comportamento na presença de diferentes níveis de compactação do solo demonstra as diferenças entre os híbridos em razão de sua finalidade de uso (relação folha/colmo). $O$ fato do híbrido 40853 ser indicado para produção de forragem e apresentar uma área foliar menor na presença de compactação do solo, representa uma desvantagem; assim sendo e para se ter maior produção de massa verde, o solo não deve apresentar limitação física alguma para seu cultivo.

Analisando a Tabela 4 observa-se, em todos os materiais de milheto estudados que, independente da densidade do solo na camada compactada, ocorreu um acúmulo maior de raízes na camada superior. Resultados semelhantes aos do presente estudo foram obtidos por Muller et al. (2001) em estudo no qual utilizaram adubos verdes de inverno, Moraes et al. (1995) com 
Tabela 4. Massa seca de raízes (MSR)* nas camadas superior, compactada e inferior de híbridos e cultivares de milheto considerando-se as densidades do solo na camada compactada

\begin{tabular}{|c|c|c|c|}
\hline \multirow{3}{*}{ Tratamento } & \multicolumn{3}{|c|}{ Camada } \\
\hline & Superior & Compactada & Inferior \\
\hline & \multicolumn{3}{|c|}{ (g) } \\
\hline & \multicolumn{3}{|c|}{ Densidade do solo: $\left(1,28 \mathrm{Mg} \mathrm{m}^{-3}\right)$} \\
\hline ADR 300 & $1,83 a b$ & $0,32 \mathrm{a}$ & $1,27 a b$ \\
\hline ADR 500 & $1,77 \mathrm{ab}$ & $0,28 \mathrm{a}$ & $0,89 \mathrm{~b}$ \\
\hline ADR 7010 & $2,07 a b$ & $0,28 \mathrm{a}$ & $1,25 a b$ \\
\hline 40425 & $2,31 a b$ & $0,42 \mathrm{a}$ & $1,32 \mathrm{ab}$ \\
\hline 40853 & $1,66 a b$ & $0,64 \mathrm{a}$ & $1,05 b$ \\
\hline 41312 & $1,15 b$ & $0,25 a$ & $1,09 \mathrm{~b}$ \\
\hline 51499 & $1,98 a b$ & $0,40 \mathrm{a}$ & $1,47 \mathrm{ab}$ \\
\hline 60018 & $1,39 \mathrm{~b}$ & $0,49 a$ & $1,49 a b$ \\
\hline 60019 & $2,59 \mathrm{a}$ & $0,48 \mathrm{a}$ & $1,76 \mathrm{a}$ \\
\hline \multirow[t]{2}{*}{ Média } & 1,86 & 0,39 & 1,28 \\
\hline & \multicolumn{3}{|c|}{ Densidade do solo: $\left(1,46 \mathrm{Mg} \mathrm{m}^{-3}\right)$} \\
\hline ADR 300 & $1,94 \mathrm{a}$ & $0,47 \mathrm{a}$ & $0,86 a b$ \\
\hline ADR 500 & $1,73 \mathrm{a}$ & $0,54 \mathrm{a}$ & $0,60 \mathrm{~b}$ \\
\hline ADR 7010 & $2,18 \mathrm{a}$ & $0,60 \mathrm{a}$ & $0,80 a b$ \\
\hline 40425 & $2,29 \mathrm{a}$ & $0,61 \mathrm{a}$ & $0,92 a b$ \\
\hline 40853 & $1,77 \mathrm{a}$ & $0,34 \mathrm{a}$ & $0,45 \mathrm{~b}$ \\
\hline 41312 & $1,54 \mathrm{a}$ & $0,37 \mathrm{a}$ & $0,54 \mathrm{~b}$ \\
\hline 51499 & $1,89 \mathrm{a}$ & $0,30 \mathrm{a}$ & $0,50 \mathrm{~b}$ \\
\hline 60018 & $2,48 \mathrm{a}$ & $0,59 a$ & $1,26 \mathrm{a}$ \\
\hline 60019 & $1,85 \mathrm{a}$ & $0,38 \mathrm{a}$ & $0,71 \mathrm{ab}$ \\
\hline \multirow{2}{*}{ Média } & 1,96 & 0,46 & 0,73 \\
\hline & \multicolumn{3}{|c|}{ Densidade do solo: $\left(1,65 \mathrm{Mg} \mathrm{m}^{-3}\right)$} \\
\hline ADR 300 & $1,62 \mathrm{~cd}$ & $0,34 a b$ & $0,210 \mathrm{~cd}$ \\
\hline ADR 500 & $2,59 \mathrm{abc}$ & $0,49 a b$ & $0,960 a b$ \\
\hline ADR 7010 & $2,97 \mathrm{ab}$ & $0,25 b$ & $0,430 \mathrm{bcd}$ \\
\hline 40425 & $3,20 \mathrm{a}$ & $0,50 a b$ & $1,130 \mathrm{a}$ \\
\hline 40853 & $1,17 \mathrm{~d}$ & $0,15 b$ & $0,029 \mathrm{~d}$ \\
\hline 41312 & $2,07 \mathrm{abcd}$ & $0,85 \mathrm{a}$ & $0,440 \mathrm{bcd}$ \\
\hline 51499 & $2,66 a b c$ & $0,48 a b$ & $0,520 \mathrm{abcd}$ \\
\hline 60018 & 2,12 abcd & $0,37 \mathrm{ab}$ & $0,820 a b c$ \\
\hline 60019 & $1,93 \mathrm{bcd}$ & $0,25 \mathrm{~b}$ & $0,580 \mathrm{abcd}$ \\
\hline \multirow[t]{2}{*}{ Média } & 2,25 & 0,40 & 0,56 \\
\hline & \multicolumn{3}{|c|}{ Densidade do solo: $\left(1,74 \mathrm{Mg} \mathrm{m}^{-3}\right)$} \\
\hline ADR 300 & $1,25 \mathrm{a}$ & $0,35 \mathrm{a}$ & $0,015 \mathrm{a}$ \\
\hline ADR 500 & $1,20 \mathrm{a}$ & $0,32 \mathrm{a}$ & $0,160 \mathrm{a}$ \\
\hline ADR 7010 & $1,58 \mathrm{a}$ & $0,35 \mathrm{a}$ & $0,008 \mathrm{a}$ \\
\hline 40425 & $1,40 \mathrm{a}$ & $0,25 \mathrm{a}$ & $0,012 \mathrm{a}$ \\
\hline 40853 & $1,03 \mathrm{a}$ & $0,21 \mathrm{a}$ & $0,020 \mathrm{a}$ \\
\hline 41312 & $1,48 \mathrm{a}$ & $0,30 \mathrm{a}$ & $0,190 \mathrm{a}$ \\
\hline 51499 & $1,67 \mathrm{a}$ & $0,17 \mathrm{a}$ & $0,040 \mathrm{a}$ \\
\hline 60018 & $2,19 a$ & $0,37 \mathrm{a}$ & $0,007 \mathrm{a}$ \\
\hline 60019 & $1,96 \mathrm{a}$ & $0,24 \mathrm{a}$ & $0,006 \mathrm{a}$ \\
\hline Média & 1,52 & 0,28 & 0,051 \\
\hline
\end{tabular}

* Médias seguidas da mesma letra na coluna não diferem entre si pelo teste de Tukey a 0,05 de probabilidade

a cultura da soja e Gonçalves et al. (2006) estudando o sistema radicular do milheto ADR500 sob compactação do solo.

Com o aumento da densidade do solo na camada compactada entre as densidades de 1,65 e $1,74 \mathrm{Mg} \mathrm{m}^{-3}$ ocorreu diminuição média de $32 \%$ na massa seca de raízes na camada superior (MSRCS), 30\% na massa seca de raízes na camada compactada (MSRCC) e $91 \%$ na massa seca de raízes na camada inferior (MSRCI) nas cultivares de milheto estudadas (Tabela 4). A diminuição no desenvolvimento das raízes foi afetada possivelmente pela redução dos macroporos, pela diminuição da concentração de oxigênio e redução da mineralização da matéria orgânica em virtude do aumento na compactação do solo, dados que se assemelham aos de Jimenez et al. (2008) em estudo com plantas de cobertura, em que o aumento da densidade do solo de 1,18 para $1,60 \mathrm{Mg} \mathrm{m}^{-3}$ diminuiu $21,25 \mathrm{e}$ $34 \%$ o crescimento de raízes nas camadas superior, compactada e inferior, respectivamente.

Analisando a Tabela 4, não foi verificada diferença significativa na produção de massa seca de raízes nas camadas avaliadas entre as cultivares e híbridos de milheto no maior nível de densidade do solo $\left(1,74 \mathrm{Mg} \mathrm{m}^{-3}\right)$ cujos resultados demonstram que as cultivares e híbridos apresentaram o mesmo comportamento na produção de MSR no maior nível de compactação. Esses resultados demonstram a capacidade do milheto de crescimento em solos com restrição física ao crescimento de raízes. Em seu estudo, Bordin et al. (2008) verificaram, em condições de campo com o objetivo de avaliar a influência da escarificação no crescimento do guandu e do milheto, que o sistema radicular do milheto se desenvolveu com maior intensidade; esses dados comprovam os resultados do presente estudo em que, na presença de limitação ao crescimento de raízes a cultura do milheto consegue desenvolver-se melhor que outras espécies.

Ocorreu diferenciação na MSRCC entre as cultivares de milheto somente na densidade de $1,65 \mathrm{Mg} \mathrm{m}^{-3}$, em que o híbrido 41312 foi o cultivar que obteve maior produção de MSR diferindo do ADR 7010, 40853 e 60019. É provável que este comportamento demonstre o potencial desta cultivar de milheto em romper camadas compactadas em níveis intermediários de compactação do solo; resultados que corroboram com o presente estudo foram obtidos por Jimenez et al. (2008), com o milheto ADR 300 e Gonçalves et al. (2006) com o milheto ADR 500.

Constatou-se um aumento de 7,3\% em média na densidade do comprimento radicular (DCR) na camada superior entre as densidades de 1,28 e 1,74 $\mathrm{Mg} \mathrm{m}^{-3}$ entre os materiais estudados (Tabela 5). Resultados semelhantes obtiveram Foloni et al. (2003) que concluíram que a DCR do milho aumentou $42 \%$ na camada superior com o aumento do nível de compactação do solo. Jimenez et al. (2008) em estudo com o milheto ADR300 no maior nível de compactação de $1,60 \mathrm{Mg} \mathrm{m}^{-3}$ respectivamente para as camadas superior, compactada e inferior, valores de 2,30; 3,12 e 2,11 $\mathrm{cm} \mathrm{cm}^{3}$ para o DCR. No presente estudo os valores médios entre os materiais estudados no maior nível de compactação do DCR na camada compactada foram de 2,95 $\mathrm{cm} \mathrm{cm}^{3}$ cujos resultados confirmam a capacidade da cultura do milheto mesmo em condições de compactação do solo emitir raízes demonstrando que deixará no solo grande quantidade de poros biológicos após o processo de decomposição de raízes. Esses poros são importantes para a infiltração de água e difusão de gases favorecendo o crescimento do sistema radicular e a melhoria das condições físicas do solo.

Ocorreu uma diminuição de 4\% em média no diâmetro radicular na camada superior entre as densidades de 1,28 e 1,74 $\mathrm{Mg} \mathrm{m}^{-3}$ nas cultivares e híbridos de milheto (Tabela 6). Dados semelhantes foram obtidos por Foloni et al. (2006) ao verificar que o diâmetro radicular da soja e da Crotalaria juncea diminuiu de acordo com o aumento dos níveis de compactação do solo na camada superior sendo que o aumento da compactação e consequente redução do tamanho dos poros, a ponto de impedir 
Tabela 5. Densidade do comprimento radicular (DCR) ${ }^{*}$ nas camadas superior, compactada e inferior, de híbridos e cultivares de milheto considerando-se as densidades do solo na camada compactada

\begin{tabular}{|c|c|c|c|}
\hline \multirow{3}{*}{ Tratamento } & \multicolumn{3}{|c|}{ Camada } \\
\hline & Superior & Compactada & Inferior \\
\hline & \multicolumn{3}{|c|}{$\mathrm{cm} \mathrm{cm}^{-3}$} \\
\hline & \multicolumn{3}{|c|}{ Densidade do solo: $\left(1,28 \mathrm{Mg} \mathrm{m}^{-3}\right)$} \\
\hline ADR 300 & $2,43 \mathrm{C}$ & $4,21 \mathrm{abc}$ & $3,03 \mathrm{a}$ \\
\hline ADR 500 & $3,61 \mathrm{bc}$ & $4,04 \mathrm{abc}$ & $2,89 \mathrm{a}$ \\
\hline ADR 7010 & $5,02 \mathrm{ab}$ & $4,92 \mathrm{ab}$ & $3,45 \mathrm{a}$ \\
\hline 40425 & $4,96 a b$ & $5,54 \mathrm{a}$ & $3,29 \mathrm{a}$ \\
\hline 40853 & $3,71 \mathrm{abc}$ & $2,86 \mathrm{bc}$ & $2,07 \mathrm{a}$ \\
\hline 41312 & $2,63 \mathrm{c}$ & $2,74 \mathrm{C}$ & $3,01 \mathrm{a}$ \\
\hline 51499 & $3,12 b c$ & $3,87 a b c$ & $2,83 \mathrm{a}$ \\
\hline 60018 & $3,17 \mathrm{bc}$ & $4,58 \mathrm{abc}$ & $3,04 \mathrm{a}$ \\
\hline 60019 & $5,79 \mathrm{a}$ & $4,97 \mathrm{ab}$ & $3,24 \mathrm{a}$ \\
\hline \multirow[t]{2}{*}{ Média } & 3,82 & 4,19 & 2,98 \\
\hline & \multicolumn{3}{|c|}{ Densidade do solo: $\left(1,46 \mathrm{Mg} \mathrm{m}^{-3}\right)$} \\
\hline ADR 300 & $2,72 b$ & $4,10 a b$ & $1,82 \mathrm{~b}$ \\
\hline ADR 500 & $3,26 a b$ & $4,15 \mathrm{ab}$ & $1,28 b$ \\
\hline ADR 7010 & 4,89 a & $5,35 a b$ & $1,89 \mathrm{~b}$ \\
\hline 40425 & $5,06 \mathrm{a}$ & $5,91 \mathrm{a}$ & $2,30 a b$ \\
\hline 40853 & $3,91 \mathrm{ab}$ & $3,55 b$ & $1,39 \mathrm{~b}$ \\
\hline 41312 & $3,01 a b$ & $3,35 \mathrm{~b}$ & $1,28 b$ \\
\hline 51499 & $4,77 \mathrm{ab}$ & $3,37 \mathrm{~b}$ & $1,28 b$ \\
\hline 60018 & $5,13 a$ & $6,22 \mathrm{a}$ & $3,86 \mathrm{a}$ \\
\hline 60019 & $4,93 \mathrm{a}$ & $4,30 \mathrm{ab}$ & $1,41 \mathrm{~b}$ \\
\hline \multirow[t]{2}{*}{ Média } & 4,18 & 4,47 & 1,83 \\
\hline & \multicolumn{3}{|c|}{ Densidade do solo: $\left(1,65 \mathrm{Mg} \mathrm{m}^{-3}\right)$} \\
\hline ADR 300 & $2,67 \mathrm{c}$ & $2,09 \mathrm{c}$ & $1,24 a b$ \\
\hline ADR 500 & $3,93 \mathrm{abc}$ & $4,32 \mathrm{ab}$ & $1,36 a b$ \\
\hline ADR 7010 & $5,68 \mathrm{a}$ & $2,86 \mathrm{bc}$ & $1,09 a b$ \\
\hline 40425 & $5,50 a b$ & $5,03 \mathrm{a}$ & $1,75 a$ \\
\hline 40853 & $3,08 \mathrm{c}$ & $2,63 \mathrm{bc}$ & $0,07 \mathrm{~b}$ \\
\hline 41312 & $4,69 a b c$ & $5,02 \mathrm{a}$ & $1,17 a b$ \\
\hline 51499 & $3,74 a b c$ & $4,12 a b c$ & $1,27 a b$ \\
\hline 60018 & $3,49 \mathrm{bc}$ & $4,45 a b$ & $1,02 a b$ \\
\hline 60019 & $3,79 a b c$ & $3,15 a b c$ & $0,97 a b$ \\
\hline \multirow[t]{2}{*}{ Média } & 4,06 & 3,74 & 1,10 \\
\hline & \multicolumn{3}{|c|}{ Densidade do solo: $\left(1,74 \mathrm{Mg} \mathrm{m}^{-3}\right)$} \\
\hline ADR 300 & 2,72 bc & $1,72 \mathrm{~b}$ & $0,37 \mathrm{a}$ \\
\hline ADR 500 & $3,89 a b c$ & $3,26 a b$ & $1,12 \mathrm{a}$ \\
\hline ADR 7010 & $5,18 \mathrm{a}$ & $4,38 \mathrm{a}$ & $0,04 \mathrm{a}$ \\
\hline 40425 & $4,63 \mathrm{ab}$ & $2,60 a b$ & $0,74 \mathrm{a}$ \\
\hline 40853 & $3,56 a b c$ & $2,40 a b$ & $0,28 \mathrm{a}$ \\
\hline 41312 & $2,40 \mathrm{c}$ & $3,55 \mathrm{ab}$ & $1,24 \mathrm{a}$ \\
\hline 51499 & $4,41 a b c$ & $2,39 a b$ & $1,14 \mathrm{a}$ \\
\hline 60018 & $5,13 \mathrm{a}$ & $1,78 \mathrm{~b}$ & $0,40 \mathrm{a}$ \\
\hline 60019 & $5,03 \mathrm{a}$ & $4,52 \mathrm{a}$ & $0,03 \mathrm{a}$ \\
\hline Média & 4,10 & 2,95 & 0,59 \\
\hline
\end{tabular}

* Médias seguidas da mesma letra na coluna não diferem entre si pelo teste de Tukey, a 0,05 de probabilidade

a passagem da raiz principal, leva a compensar este efeito pela expansão de raízes laterais com diâmetros menores.

Avaliando o valor médio do diâmetro radicular entre as diferentes cultivares e híbridos de milheto, observa-se um aumento com o aumento da densidade do solo na camada compactada. Freddi et al. (2007) observaram, em estudo para avaliar o crescimento radicular da cultura do milho em condições de compactação do solo, que o diâmetro radicular aumentou linearmente com o aumento da compactação do solo cujos dados corroboram com os do presente estudo.

Nos dois maiores níveis de compactação do solo (1,65 e $1,74 \mathrm{Mg} \mathrm{m}^{-3}$ ) tanto na camada compactada quanto na camada
Tabela 6. Diâmetro radicular* nas camadas superior, compactada e inferior, de híbridos e cultivares de milheto considerando-se as densidades do solo na camada compactada

\begin{tabular}{|c|c|c|c|}
\hline \multirow{3}{*}{ Tratamento } & \multicolumn{3}{|c|}{ Camada } \\
\hline & Superior & Compactada & Inferior \\
\hline & \multicolumn{3}{|c|}{$\mu \mathrm{m}$} \\
\hline & \multicolumn{3}{|c|}{ Densidade do solo: $\left(1,28 \mathrm{Mg} \mathrm{m}^{-3}\right)$} \\
\hline ADR 300 & $50 \mathrm{a}$ & $24 \mathrm{a}$ & $58 \mathrm{a}$ \\
\hline ADR 500 & $65 \mathrm{a}$ & $26 \mathrm{a}$ & $47 \mathrm{a}$ \\
\hline ADR 7010 & $71 \mathrm{a}$ & $24 \mathrm{a}$ & $47 \mathrm{a}$ \\
\hline 40425 & $80 \mathrm{a}$ & $25 \mathrm{a}$ & $59 \mathrm{a}$ \\
\hline 40853 & $65 \mathrm{a}$ & $34 \mathrm{a}$ & $36 \mathrm{a}$ \\
\hline 41312 & $48 \mathrm{a}$ & $24 \mathrm{a}$ & $43 \mathrm{a}$ \\
\hline 51499 & $53 \mathrm{a}$ & $23 \mathrm{a}$ & $41 \mathrm{a}$ \\
\hline 60018 & $61 \mathrm{a}$ & $30 \mathrm{a}$ & $44 \mathrm{a}$ \\
\hline 60019 & $82 \mathrm{a}$ & $24 \mathrm{a}$ & $55 \mathrm{a}$ \\
\hline \multirow[t]{2}{*}{ Média } & 63,8 & 26,0 & 47,77 \\
\hline & \multicolumn{3}{|c|}{ Densidade do solo: $\left(1,46 \mathrm{Mg} \mathrm{m}^{-3}\right)$} \\
\hline ADR 300 & $49 \mathrm{a}$ & $27 \mathrm{ab}$ & $32 a b$ \\
\hline ADR 500 & $44 \mathrm{a}$ & $25 b$ & $33 a b$ \\
\hline ADR 7010 & $66 \mathrm{a}$ & $24 b$ & $26 b$ \\
\hline 40425 & $81 \mathrm{a}$ & $38 \mathrm{a}$ & $49 a b$ \\
\hline 40853 & $65 \mathrm{a}$ & $27 \mathrm{~b}$ & $26 b$ \\
\hline 41312 & $56 \mathrm{a}$ & $26 \mathrm{~b}$ & $26 b$ \\
\hline 51499 & $65 \mathrm{a}$ & $26 \mathrm{~b}$ & $27 \mathrm{~b}$ \\
\hline 60018 & $80 \mathrm{a}$ & $26 \mathrm{~b}$ & $62 \mathrm{a}$ \\
\hline 60019 & $79 \mathrm{a}$ & $29 a b$ & $35 a b$ \\
\hline \multirow[t]{2}{*}{ Média } & 65,0 & 27,5 & 35,1 \\
\hline & \multicolumn{3}{|c|}{ Densidade do solo: $\left(1,65 \mathrm{Mg} \mathrm{m}^{-3}\right)$} \\
\hline ADR 300 & $56 \mathrm{a}$ & $29 \mathrm{a}$ & $39 \mathrm{a}$ \\
\hline ADR 500 & $63 \mathrm{a}$ & $27 \mathrm{a}$ & $25 \mathrm{a}$ \\
\hline ADR 7010 & $87 \mathrm{a}$ & $25 \mathrm{a}$ & $29 \mathrm{a}$ \\
\hline 40425 & $81 \mathrm{a}$ & $26 \mathrm{a}$ & $31 \mathrm{a}$ \\
\hline 40853 & $54 \mathrm{a}$ & $28 \mathrm{a}$ & $39 \mathrm{a}$ \\
\hline 41312 & $72 \mathrm{a}$ & $35 \mathrm{a}$ & $32 \mathrm{a}$ \\
\hline 51499 & $62 \mathrm{a}$ & $27 \mathrm{a}$ & $27 \mathrm{a}$ \\
\hline 60018 & $69 \mathrm{a}$ & $27 \mathrm{a}$ & $35 \mathrm{a}$ \\
\hline 60019 & $72 \mathrm{a}$ & $26 a$ & $35 \mathrm{a}$ \\
\hline \multirow[t]{2}{*}{ Média } & 68,4 & 27,7 & 32,4 \\
\hline & \multicolumn{3}{|c|}{ Densidade do solo: $\left(1,74 \mathrm{Mg} \mathrm{m}^{-3}\right)$} \\
\hline ADR 300 & $55 \mathrm{ab}$ & $31 \mathrm{a}$ & $34 \mathrm{a}$ \\
\hline ADR 500 & $57 a b$ & $27 \mathrm{a}$ & $25 \mathrm{a}$ \\
\hline ADR 7010 & $63 a b$ & $27 \mathrm{a}$ & $50 \mathrm{a}$ \\
\hline 40425 & $61 a b$ & $28 \mathrm{a}$ & $28 \mathrm{a}$ \\
\hline 40853 & $60 a b$ & $29 a$ & $31 \mathrm{a}$ \\
\hline 41312 & $31 \mathrm{~b}$ & $28 \mathrm{a}$ & $31 \mathrm{a}$ \\
\hline 51499 & $61 a b$ & $29 \mathrm{a}$ & $31 \mathrm{a}$ \\
\hline 60018 & $78 \mathrm{a}$ & $28 \mathrm{a}$ & $39 a$ \\
\hline 60019 & $83 \mathrm{a}$ & $28 \mathrm{a}$ & $44 \mathrm{a}$ \\
\hline Média & 61,0 & 28,0 & 34,7 \\
\hline
\end{tabular}

* Médias seguidas pela mesma letra na coluna não diferem entre si pelo teste de Tukey, a 0,05 de probabilidade

inferior, não houve diferenças entre os materiais estudados. Este comportamento demonstra ser um indicativo de que a cultura do milheto é uma espécie com potencial para estabelecer seu sistema radicular em solos compactados e, desta forma, ocorrerão formação de bioporos e melhoria nas condições físicas do solo para a cultura subsequente.

\section{Conclusões}

1. Os híbridos 40853 e 60019 apresentaram comportamento inferior aos demais híbridos e cultivares na produção de matéria 
verde e seca da parte aérea e altura de plantas na densidade de $1,65 \mathrm{Mg} \mathrm{m}^{-3}$.

2. As cultivares ADR500 e ADR300 e os híbridos 40425 e 51499 se destacaram na produção de massa verde e seca e altura de plantas na densidade de $1,65 \mathrm{~kg} \mathrm{~m}^{-3}$.

3. A maior densidade de comprimento radicular média entre as cultivares de milheto foi verificada na densidade do solo de $1,46 \mathrm{Mg} \mathrm{m}^{-3}$.

4. A cultura do milheto demonstrou potencial como planta descompactadora do solo.

\section{Literatura Citada}

Amaral, J. F. T. Eficiência de produção de raízes, absorção, translocação e utilização de nutrientes em cultivares de café arábica. Viçosa: UFV, 2002. 97p. Tese Doutorado

Boer, C. A.; Assis, R. L.; Silva, G. P.; Braz, A. J. B. P.; Barroso, A. L. L.; Cargnelutti Filho, A.; Pires, F. R. Ciclagem de nutrientes por plantas de cobertura na entressafra em um solo de cerrado. Pesquisa Agropecuária Brasileira, v.42, p.1269-1276, 2007.

Bordin, I.; Neves, C. S. V. J.; Francio Filho, P.; Preti, E. A.; Cardoso, C. Crescimento de milheto e guandu, desempenho de plantas cítricas e propriedades físicas do solo escarificado em um pomar. Revista Brasileira de Ciência do Solo, v.32, p.1409-1418, 2008.

EMBRAPA - Empresa Brasileira de Pesquisa Agropecuária. Centro Nacional de Pesquisa de Solos. Manual de métodos de análises de solo. 2.ed., Rio de Janeiro: EMBRAPA, 1997. 212p.

Foloni, J. S. S.; Calonego, J. C.; Lima, S. L. Efeito da compactação do solo no desenvolvimento aéreo e radicular de cultivares de milho. Pesquisa Agropecuária Brasileira, v.38, p.947-953, 2003.

Foloni, J. S. S.; Lima, S. L.; Bull, L. T. Crescimento aéreo e radicular da soja e de plantas de cobertura em camadas compactadas de solo. Revista Brasileira de Ciência do Solo, v.30, p.49-57, 2006.

Freddi, O. S.; Centurion, J. F.; Beutler, A. N; Aratani, R. G.; Leonel, C. L. Compactação do solo no crescimento radicular e produtividade da cultura do milho. Revista Brasileira de Ciência do Solo, v.31, p.627-636, 2007.
Gonçalves, W. G.; Jimenez, R. L.; Araújo Filho, J. V.; Assis, R. L.; Silva, G. P.; Pires, F. R. Sistema radicular de plantas de cobertura sob compactação do solo. Engenharia Agrícola, v.26, p.67-75, 2006.

Guimarães, C. M.; Stone, L. F.; Moreira, J. A. A. Compactação do solo na cultua do feijoeiro. II: Efeito sobre o desenvolvimento radicular e da parte aérea. Revista Brasileira Engenharia Agrícola e Ambiental, v.6, p.213-218, 2002.

Jimenez, R. L.; Gonçalves, W. G.; Araujo Filho, J. V.; Assis, R. L.; Pires, F. R.; Silva, G. P. Crescimento de plantas de cobertura sob diferentes níveis de compactação em um Latossolo Vermelho. Revista Brasileira de Engenharia Agrícola Ambiental, v.12, p.116-121, 2008.

Moraes, M. H.; Benez, S. H.; Libardi, P. L. Efeitos da compactação em algumas propriedades físicas do solo e seu reflexo no desenvolvimento das raízes de plantas de soja. Bragantia, v.54, p.393-403, 1995.

Muller, M. M. L.; Ceccon, G.; Rosolem, C. A. Influência da compactação do solo em subsuperfície sobre o crescimento aéreo e radicular de plantas de adubação verde de inverno. Revista Brasileira de Ciência do Solo, v.25, p.531-538, 2001.

Nogueira, J. B. Mecânica dos solos: ensaios de laboratório. São Carlos: Escola de Engenharia de São Carlos, USP, 1995. 248p.

Piffer, C. R.; Benez, S. H.; Bertolini, E. V.; Cominetti, F. R.; Silva, P. R. A. Crescimento radicular de três espécies de cobertura vegetal em camadas de solo compactadas artificialmente. Revista Varia Scientia Agrárias, v.1, p.31-43, 2010.

Pires, F. R.; Assis, R. L.; Silva, G. P.; Braz, A. J. B. P.; Santos, S. C.; Vieira Neto, S. A.; Sousa, J. P. G. de. Desempenho Agronômico de variedades de milheto em razão da fenologia em pré-safra. Bioscience Journal, v.23, p.41-49, 2007.

Ribeiro, M. A. V. Resposta da soja e do eucalipto a fósforo em solos de diferentes texturas, níveis de densidade e de umidade. Lavras: UFLA, 1999. 71p. Tese Doutorado

Silva, R. H.; Rosolem, C. A. Crescimento radicular de espécies utilizadas como cobertura decorrente da compactação do solo. Revista Brasileira de Ciência do Solo, v.25, p.253260, 2001.

Stone, L. F.; Guimarães, C. M.; Moreira, J. A. A. Compactação do solo na cultura do feijoeiro: I. nas propriedades físicohídricas do solo. Revista Brasileira de Engenharia Agrícola e Ambiental, v.6, p.213-218, 2002.

Vargas, M. Introdução à mecânica dos solos. São Paulo: McGraw-Hill do Brasil, 1977. 509p. 